\title{
No son más, no son menos, todos somos médicos sin importar el género
}

\author{
They are not more, they are not less, \\ we are all doctors regardless of gender
}

\author{
Federico Leopoldo Rodríguez Weber*
}

En medicina, desde hace tiempo, reconocemos el papel de la mujer como profesional $y$, desde hace mucho, las profesionistas mujeres tienen el mismo valor que los profesionistas hombres. Sin embargo, reconocemos que sólo en algunas instituciones no se les valora de igual forma, y por eso, ahí es donde la lucha debe continuar. Si bien el movimiento de "igualdad" entre hombres y mujeres tiene particular interés en ello, en estos tiempos vale la pena expresar, desde nuestra propia óptica, algunas ideas vinculadas a los diferentes tópicos en relación al tema.

La matrícula de estudiantes de género femenino en las universidades con escuelas de medicina o facultades de medicina, a partir del presente siglo, se ha incrementado sustancialmente; actualmente la presencia del género femenino ocupa entre el 50 al $70 \%$ de la matrícula. Esto mismo sucede en la ocupación de plazas para la realización de residencias médicas (Figura 1), y cada día las mujeres se encuentran mejor posicionadas, pues ocupan puestos directivos e intermedios en las diferentes instituciones de salud del país. ${ }^{1}$

En el ejercicio de la medicina práctica, en el contacto con los pacientes, es donde más se han ido desplazando los espacios a los médicos de género masculino, a pesar de que existen especialidades que tradicionalmente se vinculan más con el género femenino y otras que se vinculan más con el género masculino; esta situación paulatinamente

\footnotetext{
* Médico Internista. Profesor Titular la Cátedra de "Propedéutica y Nosología". Profesor adjunto de la Residencia de Medicina Interna del Hospital Ángeles Pedregal de la Facultad Mexicana de Medicina de la Universidad La Salle. Ciudad de México, México.
}

Correspondencia:

Dr. Federico Leopoldo Rodríguez Weber

Correo electrónico: fweber@saludangeles.com

Aceptado: 07-04-2020.

www.medigraphic.com/actamedica ha tendido a balancearse, haciendo que las especialidades conocidas popularmente como feminizadas (como dermatología, oftalmología o genética) y otras conocidas como masculinizadas (como cirugía general, ortopedia, neurocirugía, medicina crítica y de urgencias) sean hoy especialidades en las que las mujeres y los hombres son aceptados con igualdad de oportunidades, requiriendo únicamente de demostrar su valía en el aspecto académico, científico y de destrezas.

Desde hace tiempo, las mujeres se han ido abriendo camino en el área de la salud, viviendo hoy, en la gran mayoría de las instituciones, una competencia sana con los hombres, lo que se traduce en igualdad de condiciones para competir por los puestos de liderazgo y de toma de decisiones. ${ }^{2}$

Lo cierto es que las mujeres son madres y los hombres nunca podrán serlo, y viceversa, los hombres son padres y las mujeres nunca podrán serlo. Esto hace que los roles que tienen en la sociedad deban respetarse, por lo que, con mucha frecuencia, las mujeres optan por balancear el trabajo y la vida familiar de forma diferente al hombre de la misma manera que, en algunas ocasiones, las mujeres eligen tener periodos de retiro laboral como consecuencia de las exigencias temporales de su hogar o como respuesta a la necesidad de mantener un equilibrio social-laboral. Ello influye posiblemente en el tipo de trabajos y compromisos que pueden ser tomados por ellas. Pero esto sólo es un grupo de mujeres, pues otras muchas, en la vida moderna, posiblemente el grupo mayoritario deciden no tener hijos o bien deciden adquirir formatos diferentes en este proceso, haciéndolas igualmente competitivas con los hombres ante cualquier trabajo. ${ }^{3}$

Otro punto que considero de interés y que es importante resaltar es que, si bien debemos competir por los trabajos, las evaluaciones para las decisiones deben basarse exclusivamente en el contenido curricular de cada competidor, sin importar el género, así como en su perfil académico y profesional; además la remuneración debe ser igual para hombres como para mujeres; en el trato diario el personal 


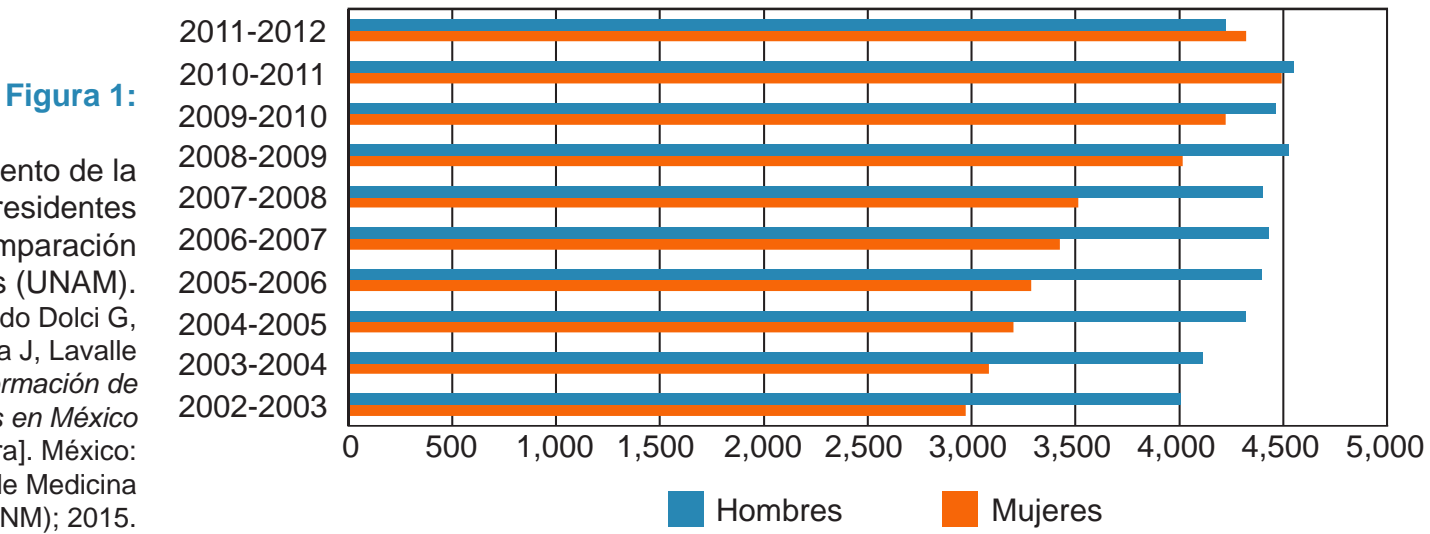

debe distinguir que el trato de cualquier persona deberá ser de acuerdo con su género, dando al trabajo y al ejercicio de la medicina un toque personalizado y en el que el género quede reconocido y respetado, no afectando ni las decisiones, ni las actividades de trabajo, solamente de manera parcial la forma en el trato y en el respeto para ambos géneros.

El momento que vivimos brinda a la medicina una oportunidad como posiblemente ninguna otra profesión la tenga claro: el reconocer lo importante de la presencia del género femenino en todos los niveles del ejercicio de la profesión, asegurando que, los que están, son los mejores, pues no importa el número de un género o de otro, aun sabiendo que los que ocupan el puesto — sin importar el género- cumplen con el perfil adecuado para cubrirlo. Por esta razón, los mejores son los que están, así se permite que las instituciones sean plurales, seguras y de calidad. Un ejemplo de esto es el comportamiento de la ocupación de plazas, en los últimos años, en el Grupo Ángeles, Servicios de Salud (Tabla 1).

Estas ideas - así como ponerlas en práctica y respetarlas deben permear a las nuevas generaciones, desde las universidades y desde las instituciones de salud hasta los mismos profesionistas sin importar ni la edad ni el género al que pertenecen, ya que las mujeres profesionistas médicas, desde ser médicos generales, pasando por especialistas, directivos o altos directivos, no son más, ni son menos. Así, estamos obligados todos los que nos dedicamos a esta profesión a que defendamos el respeto a esta igualdad tan politizada en otros ámbitos, lo que impide que se desvir-
Tabla 1: Egresados de las residencias médicas

por género en el Grupo Ángeles Servicios de

Salud (GASS). Dirección de Educación.

\begin{tabular}{|cccc}
\hline Año & $\begin{array}{c}\text { Total de } \\
\text { egresados }\end{array}$ & Mujer & Hombre \\
\hline 2015 & 94 & 44 & 50 \\
2016 & 112 & 47 & 65 \\
2017 & 97 & 48 & 49 \\
2018 & 109 & 56 & 53 \\
2019 & 105 & 52 & 53 \\
2020 & 123 & 65 & 58 \\
\hline
\end{tabular}

túen los principios académicos, humanos y de justicia de nuestra profesión.

\section{REFERENCIAS}

1. Fajardo Dolci G, Santacruz Varela J, Hernández Torres F. Conclusiones y lecciones aprendidas de la experiencia nacional. En: Fajardo Dolci G, Santacruz Varela J, Lavalle Montalvo C. La formación de médicos especialistas en México [documento de postura]. México: Academia Nacional de Medicina (ANM); 2015.

2. Somoza MJ, Quarracino C. Feminización de la neurología en Argentina. Neurol Arg. 2017; 9: 3-9.

3. Pingleton SK, Jones EV, Rosolowski TA, Zimmerman MK. Silent bias: challenges, obstacles, and strategies for leadership development in academic medicine-lessons from oral histories of women professors at the university of Kansas. Acad Med. 2016; 91 (8): 1151-1157. doi: 10.1097/ACM.0000000000001125. 